\title{
Transport Characteristics of Ribavirin in Human Erythrocyte Membrane Vesicles
}

\author{
Ryoko Yumoto, Eri Kimura, Satoshi Suzuki, Hiroaki Imaoka, \\ Junya Nagai, and Mikihisa Takano*
}

Department of Pharmaceutics and Therapeutics, Graduate School of Biomedical Sciences, Hiroshima University 1-2-3 Kasumi, Minami-ku, Hiroshima 734-8553, Japan

Transport characteristics of ribavirin in human erythrocytes were evaluated using rightside-out membrane vesicles (ROVs) prepared from fresh blood, and compared with those in intact erythrocytes. $\left[{ }^{3} \mathrm{H}\right]$ Ribavirin uptake by ROVs at $23{ }^{\circ} \mathrm{C}$ was fairly rapid, and reached equilibrium at about $30 \mathrm{sec}$. The uptake of $\left[{ }^{3} \mathrm{H}\right]$ ribavirin by ROVs showed saturation kinetics with the Km value of $1.9 \mathrm{mM}$. The uptake by ROVs was inhibited by uridine (a typical substrate of equilibrative nucleoside transporter ENT1), S-(4-nitrobenzyl)-6-thioinosine (a specific inhibitor of ENT1), and dipyridamole (an inhibitor of ENT1). These characteristics of $\left[{ }^{3} \mathrm{H}\right]$ ribavirin transport in ROVs were similar to those observed in intact erythrocytes, though the affinity of $\left[{ }^{3} \mathrm{H}\right]$ ribavirin to the transport system and sensitivity to various inhibitors were lower in ROVs. Next, the interaction of ribavirin with ATP-dependent efflux transporters was evaluated using inside-out membrane vesicles (IOVs). Ribavirin weakly inhibited ATP-dependent uptake of methotrexate by multidrug resistance-associated protein (MRP) 4, but not the uptake of 5-(and 6)-carboxy-2', 7'-dichlorofluorescein by MRP5, by IOVs. However, ATP-dependent uptake of $\left[{ }^{3} \mathrm{H}\right]$ ribavirin by IOVs was not observed. These results suggest that ribavirin is transported by ENT1 across human erythrocyte membranes, while ATP-dependent efflux transporters would not be involved in ribavirin transport.

Key words : ribavirin / erythrocyte membranes / rightside-out vesicles / equilibrative nucleoside transporter / efflux transporter

\section{Introduction}

Ribavirin (1- $\beta$-D-ribofuranosyl-1,2,4-triazole-3carboxamide), a purine nucleoside analogue having a broad antiviral spectrum, is active in vitro and in vivo against a variety of DNA and RNA viruses. A combination of oral ribavirin with subcutaneous peginterferon $\alpha-2 \mathrm{~b}$ or peginterferon $\alpha-2 \mathrm{a}$ is now a standard therapy in treating patients with chronic intractable hepatitis $\mathrm{C}$, particularly with hepatitis $\mathrm{C}$ of genotype $1 \mathrm{~b}$ and high viral titers. In this combination therapy, however, ribavirin-specific red blood cell disorders such as erythrocytopenia and decreases in hematocrit and hemoglobin levels are common and severe enough to require dose reduction in approximately $7 \sim 15 \%$ of patients ${ }^{1,2)}$. It

* Corresponding Author

Tel: $+81-82-257-5315$

Fax: $+81-82-257-5319$

E-mail: takanom@hiroshima-u.ac.jp has been shown that ribavirin is taken up by human erythrocytes and is phosphorylated to ribavirin triphosphate $^{3,4)}$. Because dephosphorylating enzymes such as alkaline phosphatase are lacking in human erythrocytes, phospholylated metabolites of ribavirin highly accumulates in the cells, 5). Though the precise mechanisms underlying ribavirin-induced erythrocytopenia are still unknown, the first step of the hematological toxicity should be the transport of ribavirin into the erythrocytes.

So far, only a limited study on the transport of ribavirin in human erythrocytes has been reported. Jarvis et al.6) examined ribavirin uptake by using washed, intact erythrocytes and inhibitor oil-stop methods. The uptake of ribavirin was saturable with a $\mathrm{Km}$ value of $0.44 \mathrm{mM}$, was inhibited by adenosine and S-(4nitrobenzyl)-6-thioinosine (NBMPR), and was transstimulated by uridine. Based on these results, they concluded that ribavirin is taken up by human erythrocytes by NBMPR-sensitive nucleoside transporter 
(equilibrative nucleoside transporter 1; ENT1). However, information concerning ribavirin transport in human erythrocytes is still lacking. In addition, as far as we know, there is no study that has examined ribavirin transport at the erythrocyte membrane level using membrane vesicles. These backgrounds prompted us to examine uridine, a typical substrate of ENT1, and ribavirin transport using human erythrocyte membrane vesicles.

During the above mentioned studies, we have noticed that uridine can be transported by ENT1 at icecold temperatures. In other words, ENT1 is functioning at ice-cold temperatures near $0{ }^{\circ} \mathrm{C}$. Surprisingly, even overshoot uptake (uphill transport) of uridine was observed at ice-cold temperatures under certain conditions $^{7}$. These studies have given us important information in order to estimate erythrocyte ENT1 function properly; addition of an ENT1 inhibitor such as NBMPR in the stop solution (the solution to stop the uptake reaction and to wash the membrane vesicles) is essential. In fact, about $90 \%$ of uridine taken up by erythrocyte membrane vesicles was effluxed during washing process using ice-cold stop solution without NBMPR, and therefore it was impossible to evaluate transport characteristics of uridine at the membrane level ${ }^{7)}$. We suppose that this may be one of the reasons why no study on ribavirin transport in erythrocyte membrane vesicles has been reported so far.

In this study, we have evaluated the transport characteristics of ribavirin using rightside-out membrane vesicles (ROVs) prepared from human blood, and compared with those in intact erythrocytes. In addition, the interaction of ribavirin with efflux transporters expressed in erythrocyte membranes such as multidrug resistance-associated protein (MRP) 4 was also examined. Our results suggest that ribavirin is transported by ENT1 across human erythrocyte membranes, and ATP-dependent efflux transporters would not be involved in ribavirin transport in erythrocytes.

\section{Experimental Section}

\subsection{Materials}

$\left[{ }^{3} \mathrm{H}\right]$ Ribavirin $(9.6 \mathrm{Ci} / \mathrm{mmol})$ was obtained from Moravek Biochemicals (Brea, CA, USA). Unlabeled ribavirin and 5-(and 6)-carboxy-2', 7'-dichlorofluorescein (CDCF) and methotrexate (MTX) were purchased from Wako Pure Chemical Industries (Osaka, Japan).
S-(4-nitrobenzyl)-6-thioinosine (NBMPR) and dipyridamole were purchased from Sigma Chemical Co. (St. Louis, MO, USA). ACS II was purchased from Amersham Pharmacia Biotech (Buckinghamshire, UK). All other chemicals used for the experiments were of the highest purity available.

\subsection{Preparation of washed, intact erythrocytes}

Fresh blood was collected into tubes containing EDTA from healthy volunteers after obtaining written informed consent. The study was approved by Ethics Committee of Hiroshima University. Erythrocytes from $5 \mathrm{ml}$ of fresh blood were washed three times with $50 \mathrm{ml}$ of buffer A $(140 \mathrm{mM} \mathrm{NaCl}, 5 \mathrm{mM} \mathrm{KCl}, 20 \mathrm{mM}$ Tris/HCl, $2 \mathrm{mM} \mathrm{MgCl} 2,0.1 \mathrm{mM}$ EDTA, $\mathrm{pH}$ 7.4) by centrifugation $(1,500 \mathrm{~g}, 10 \mathrm{~min})$ at room temperature. The supernatant was carefully aspirated off to remove the buffy coat and plasma.

\subsection{Preparation of rightside-out human ery- throcyte membrane vesicles (ROVs)}

ROVs were prepared from human erythrocytes by the method described previously ${ }^{7,8)}$. Briefly, $5 \mathrm{ml}$ of fresh blood was washed with $25 \mathrm{ml}$ of buffer B (137 $\mathrm{mM} \mathrm{NaCl}, 2.7 \mathrm{mM} \mathrm{KCl}, 10.6 \mathrm{mM} \mathrm{Na} 2 \mathrm{HPO}_{4}, 8.5 \mathrm{mM}$ $\mathrm{KH}_{2} \mathrm{PO}_{4}, 1 \mathrm{mM} \mathrm{MgCl} 2,100 \mu \mathrm{M}$ EGTA, pH 7.4) by centrifugation. Erythrocytes were lysed by incubation with $120 \mathrm{ml}$ of lysis buffer (50-fold diluted buffer B) for 60 min on ice. The lysate was washed by centrifugation with buffer B, and the pellet was incubated with $20 \mathrm{ml}$ of buffer $\mathrm{B}$ for $45 \mathrm{~min}$ at $37^{\circ} \mathrm{C}$. After centrifugation, the pellet was washed with buffer C (100 mM mannitol, 10 mM HEPES/Tris, pH 7.4) by centrifugation. The final pellet containing ROVs was stored at $-80^{\circ} \mathrm{C}$ until use.

\subsection{Preparation of inside-out human erythro- cyte membrane vesicles (IOVs)}

IOVs were prepared from human erythrocytes by the method described previously ${ }^{7,9)}$. Briefly, erythrocytes from $5 \mathrm{ml}$ of fresh blood were washed with $40 \mathrm{ml}$ of $0.9 \% \mathrm{NaCl}$ by centrifugation. The cell suspension in one volume of $51 \mathrm{mM}$ sodium phosphate buffer $(\mathrm{pH}$ 8.0) was rapidly mixed with 8.5 volumes of ice-cold lysis buffer (5.1 mM sodium phosphate buffer, $\mathrm{pH}$ 8.0). The lysate was stirred for $15 \mathrm{~min}$ on ice, and the unsealed ghosts were washed with $60 \mathrm{ml}$ of ice-cold lysis buffer by centrifugation. To initiate vesiculation, the pelleted unsealed ghosts were mixed with two vol- 
umes of $0.51 \mathrm{mM}$ sodium phosphate buffer ( $\mathrm{pH} 9.7$ ). After 1.5 hours incubation on ice followed by $30 \mathrm{~min}$ at $37^{\circ} \mathrm{C}$, the vesicles formed were pelleted by centrifugation and the pellet was dispersed by vigorous vortex mixing. The vesicles were washed with buffer $\mathrm{C}$ by centrifugation. The final pellet containing IOVs was suspended in $300 \mu 1$ of buffer $\mathrm{C}$ and stored at $-80^{\circ} \mathrm{C}$ until use.

\subsection{Uptake study by erythrocytes}

After preincubation for $10 \mathrm{~min}$ at $23^{\circ} \mathrm{C}, 0.1 \mathrm{ml}$ of cell suspension (haematocrit 30\%) in buffer A was mixed quickly with $0.1 \mathrm{ml}$ of buffer A containing $15 \mu \mathrm{M}$ $\left[{ }^{3} \mathrm{H}\right]$ ribavirin with or without various concentrations of unlabeled uridine, ribavirin, NBMPR or dipyridamole. After incubation for $5 \mathrm{sec}$ at $23^{\circ} \mathrm{C}$, uptake reaction was terminated by the inhibitor-oil stop method ${ }^{7}$.

\subsection{Uptake study by ROVs}

The uptake of ribavirin by ROVs was measured by a rapid filtration technique, as described previously ${ }^{7,10)}$. Briefly, $3 \mathrm{mg}$ protein $/ \mathrm{ml}$ of ROVs was prepared in buffer D (100 mM KCl, $100 \mathrm{mM}$ mannitol, $10 \mathrm{mM}$ HEPES/Tris, $\mathrm{pH}$ 7.4), and substrate mixtures containing $15 \mu \mathrm{M}\left[{ }^{3} \mathrm{H}\right]$ ribavirin were prepared in buffer $\mathrm{E}$ (100 mM NaCl, $100 \mathrm{mM}$ mannitol, $10 \mathrm{mM}$ HEPES/ Tris, $\mathrm{pH}$ 7.4) on ice before the experiments. After preincubation for $10 \mathrm{~min}$ at $23{ }^{\circ} \mathrm{C}$, the substrate mixture $(80 \mu 1)$ and ROVs $(20 \mu 1)$ were mixed and incubated for $15 \mathrm{sec}$. The incubation was stopped by diluting the reaction mixture with $1 \mathrm{ml}$ of an ice-cold stop solution containing $1 \mu \mathrm{M}$ NBMPR in buffer $\mathrm{D}$. In the inhibition studies, the half-maximal inhibitory concentration $\left(\mathrm{IC}_{50}\right)$ value was determined through curve-fitting to the Hill equation, as described previously ${ }^{7}$.

\subsection{Uptake studies by IOVs}

The uptake of a substrate by IOVs was measured by a rapid filtration technique, as described previous$1 \mathrm{y}^{7,11,12)}$. Briefly, $3 \mathrm{mg}$ protein $/ \mathrm{ml}$ of IOVs was prepared in buffer $\mathrm{D}$, and substrate mixtures containing 15 $\mu \mathrm{M}$ MTX, $5 \mu \mathrm{M}$ CDCF or $15 \mu \mathrm{M}\left[{ }^{3} \mathrm{H}\right]$ ribavirin were prepared in buffer $\mathrm{F}(80 \mathrm{mM} \mathrm{KCl}, 100 \mathrm{mM}$ mannitol, 10 $\mathrm{mM} \mathrm{MgCl}, 10 \mathrm{mM}$ phosphocreatine disodium salt, 100 $\mu \mathrm{g} / \mathrm{ml}$ creatine phosphokinase, $1 \mathrm{mM}$ ATP or AMP, $10 \mathrm{mM}$ HEPES/Tris, $\mathrm{pH}$ 7.4) on ice before the experiments. After preincubation for $10 \mathrm{~min}$ at $37^{\circ} \mathrm{C}$, the reaction was initiated by adding the substrate mixture $(80$ $\mu 1)$ to IOVs $(20 \mu 1)$ at $37^{\circ} \mathrm{C}$. At the stated times, the incubation was stopped by diluting the reaction mixture with $1 \mathrm{ml}$ of the ice-cold stop solution (buffer D). Other processes were the same as for the uptake study with ROVs.

\subsection{Analytical methods}

After the uptake experiments, the uptake amount of $\left[{ }^{3} \mathrm{H}\right]$ ribavirin, $\mathrm{CDCF}$ and MTX was measured by liquid scintillation counting, Hitachi fluorescence spectrophotometer F-3000 (Tokyo, Japan) (Ex 500 nm, Em 523 $\mathrm{nm})$, and HPLC (304 nm), respectively, as described previously $^{7,11,12)}$. Protein concentrations were measured by the method of Bradford with bovine serum albumin as a standard ${ }^{13)}$.

\subsection{Statistical analysis}

The data were expressed as the mean \pm S.E.. Statistical analysis was performed by Student's t-test, or by one-way analysis of variance followed by the Tukey test for multiple comparisons. The level of significance was set at $\mathrm{p}<0.05$ or at $\mathrm{p}<0.01$.

\section{Results and Discussion}

\subsection{Effect of NBMPR in the stop solution and time-dependence of ribavirin uptake by ROVs}

In order to confirm whether ribavirin is also efficiently effluxed from ROVs at ice-cold temperatures during washing process in the absence of NBMPR, the effects of various concentrations of NBMPR in the stop solution on the apparent uptake of $\left[{ }^{3} \mathrm{H}\right]$ ribavirin were examined (Fig. 1A). When ice-cold stop solution without NBMPR was used, about $90 \%$ of $\left[{ }^{3} \mathrm{H}\right]$ ribavirin taken up by ROVs was effluxed during washing process. This value was similar to that observed in uridine transport study ${ }^{7}$. NBMPR added in the stop solution inhibited the efflux in a concentration-dependent fashion. Thus, as reported recently ${ }^{7}$, ENT1 is functioning at icecold temperatures near $0{ }^{\circ} \mathrm{C}$, and addition of NBMPR in the stop solution is essential for evaluating ribavirin transport in erythrocyte membranes. In the following experiments, therefore, ice-cold stop solution containing $1 \mu \mathrm{M}$ NBMPR was employed. Figure $1 \mathrm{~B}$ shows the time-course of $\left[{ }^{3} \mathrm{H}\right]$ ribavirin uptake by ROVs at $23{ }^{\circ} \mathrm{C}$. $\left[{ }^{3} \mathrm{H}\right]$ Ribavirin uptake was fairly rapid, and reached equilibrium at about $30 \mathrm{sec}$. For the estima- 

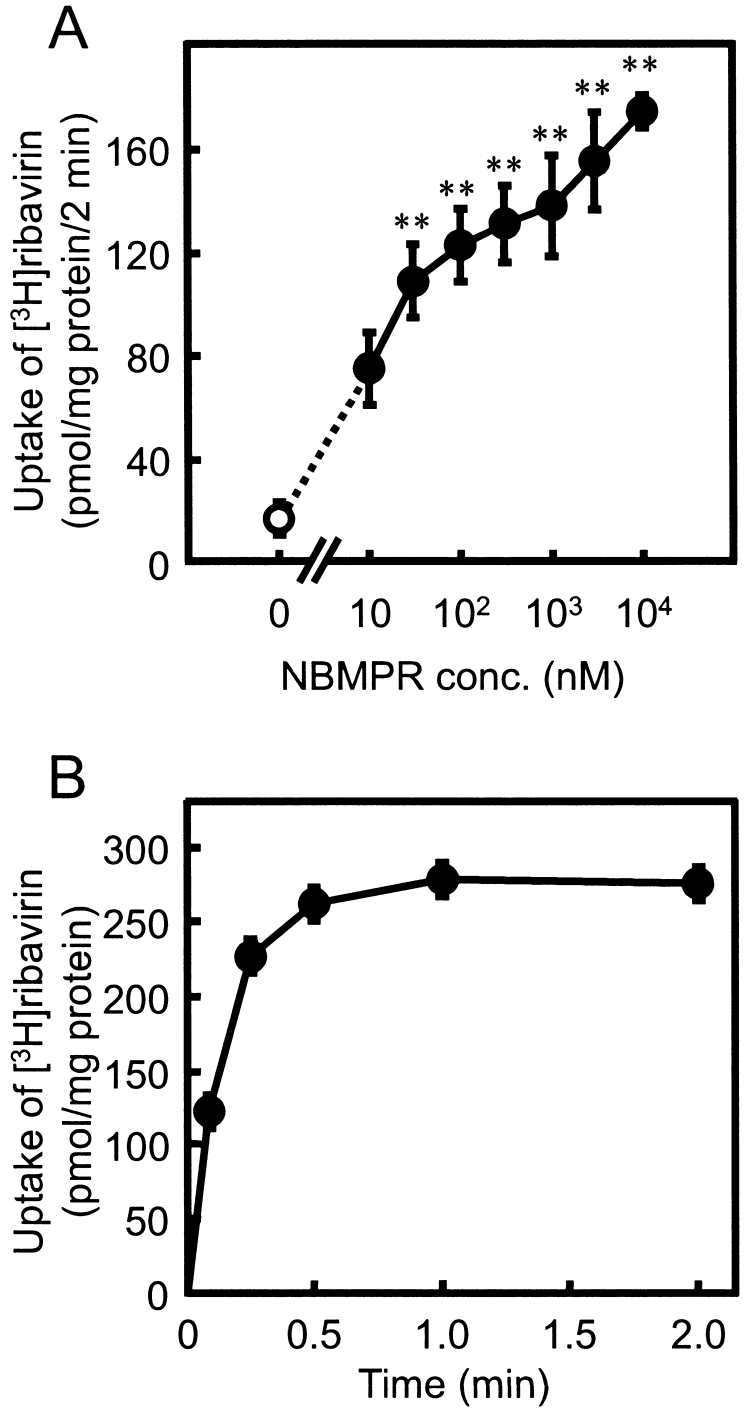

Fig. 1 A: Effect of NBMPR added to ice-cold stop solution on the apparent $\left[{ }^{3} \mathrm{H}\right]$ ribavirin uptake by ROVs. ROVs were incubated with $15 \mu \mathrm{M}\left[{ }^{3} \mathrm{H}\right]$ ribavirin at $23{ }^{\circ} \mathrm{C}$ for $2 \mathrm{~min}$. The incubation was stopped by diluting the reaction mixture with $1 \mathrm{ml}$ of ice-cold stop solution without (control, open circle) or with (closed circle) various concentrations of NBMPR. Each value represents the mean \pm S.E. of 3 determinations. $* * \mathrm{p}<0.01$, significantly different from the control.

B: Time-dependence of $\left[{ }^{3} \mathrm{H}\right]$ ribavirin uptake by human ROVs. The uptake of $15 \mu \mathrm{M}\left[{ }^{3} \mathrm{H}\right]$ ribavirin was measured at $23{ }^{\circ} \mathrm{C}$. At the stated time, the incubation was stopped by diluting the reaction mixture with $1 \mathrm{ml}$ of ice-cold stop solution containing $1 \mu \mathrm{M}$ NBMPR. Each value represents the mean \pm S.E. of 3 determinations.

tion of the initial rate of uptake in the following experiments, the uptake for $15 \mathrm{sec}$ was measured. However, it should be mentioned that even at $15 \mathrm{sec}$, there may
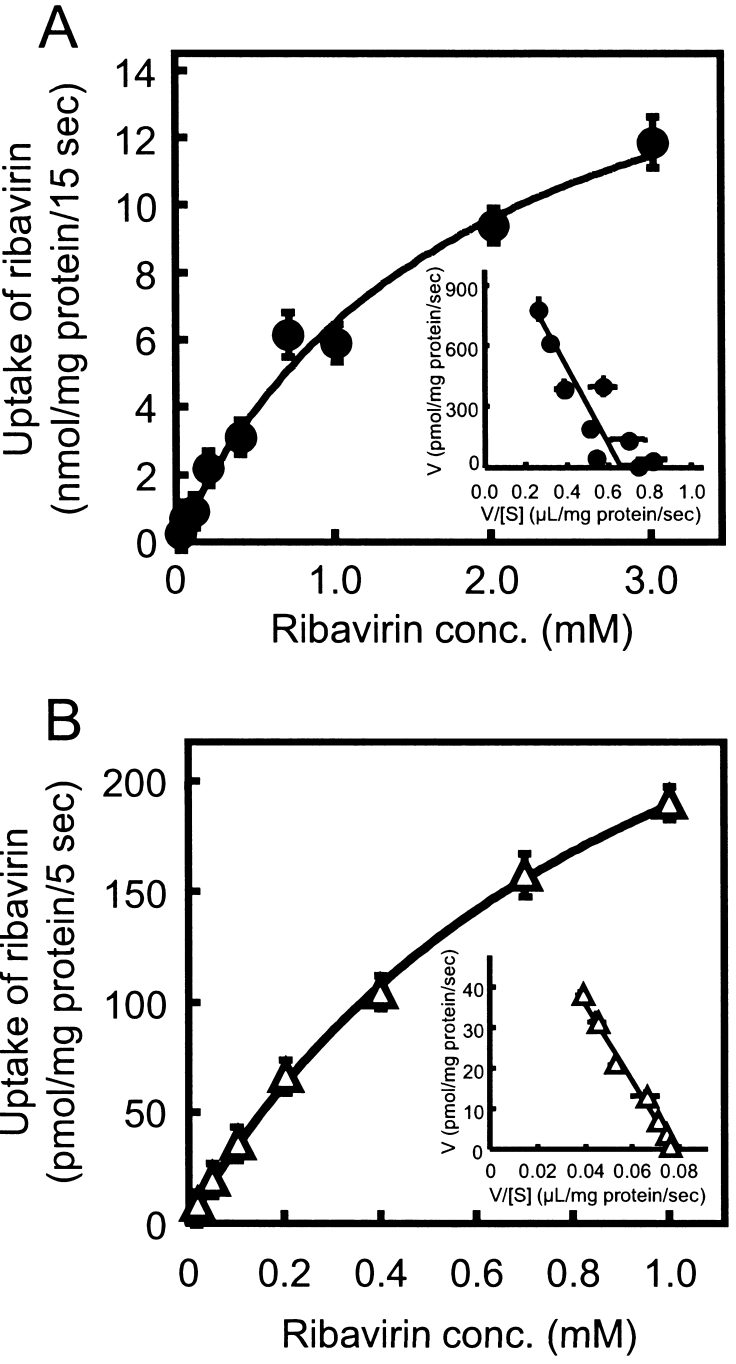

Fig. 2 Concentration-dependence of $\left[{ }^{3} \mathrm{H}\right]$ ribavirin uptake by ROVs (A) and erythrocytes (B) at $23^{\circ} \mathrm{C}$. A: The uptake of ribavirin by ROVs for $15 \mathrm{sec}$ at concentrations between $15 \mu \mathrm{M}$ and $3 \mathrm{mM}$ was determined at $23^{\circ} \mathrm{C}$. B: The uptake of ribavirin by erythrocytes for $5 \mathrm{sec}$ at concentrations between $15 \mu \mathrm{M}$ and $1 \mathrm{mM}$ was determined at $23^{\circ} \mathrm{C}$. The inset shows EadieHofstee plot. Each value represents the mean \pm S.E. of 3 determinations.

be deviation from the linear range of the uptake rate, and the uptake values may be underestimated to some extent.

\subsection{Concentration-dependence of ribavirin uptake by ROVs and erythrocytes}

The concentration-dependence of ribavirin uptake by ROVs was examined. As shown in Fig. $2 \mathrm{~A}$, $\left[{ }^{3} \mathrm{H}\right]$ ribavirin uptake showed saturation kinetics, and the $\mathrm{Km}$ (Michaelis-Menten constant) and Vmax (maximum velocity) values were calculated to be $1.9 \mathrm{mM}$ and 1.2 

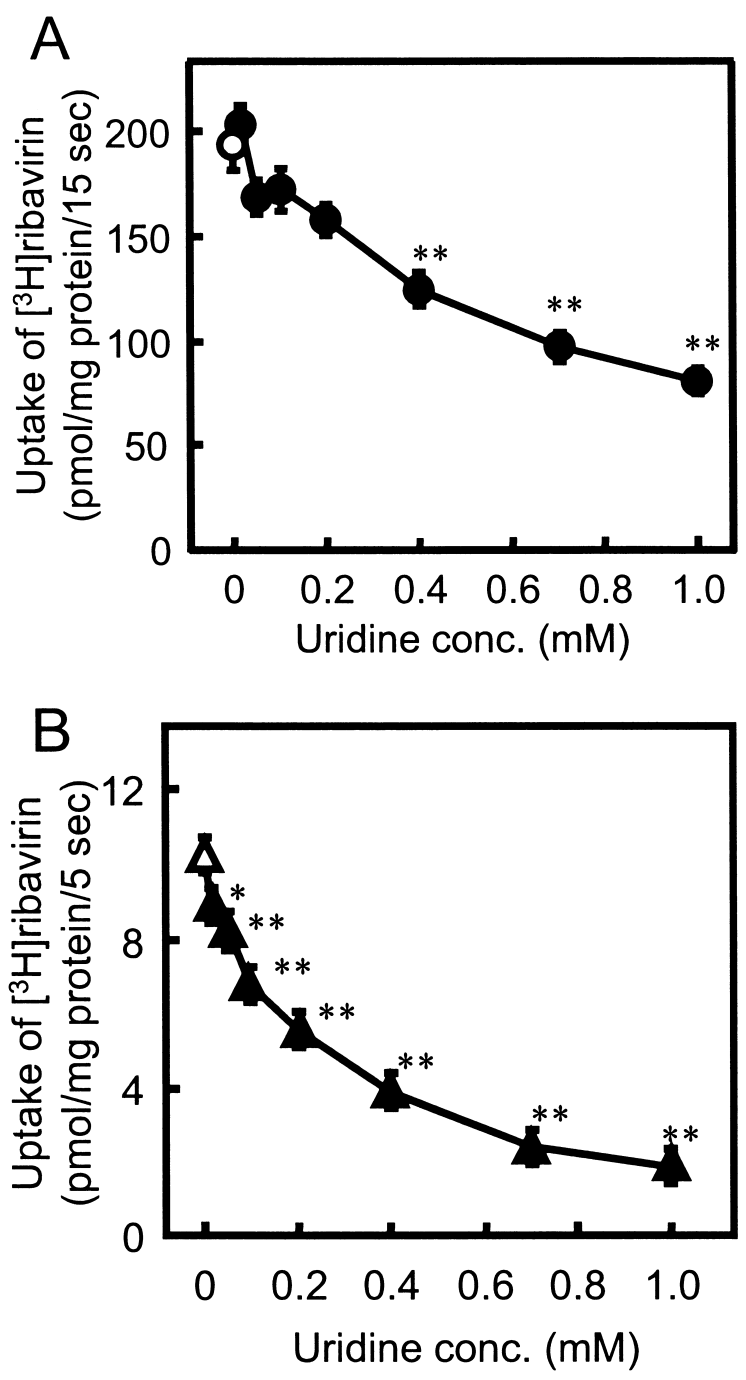

Fig. 3 Effects of uridine on $\left[{ }^{3} \mathrm{H}\right]$ ribavirin uptake by ROVs (A) and erythrocytes (B). ROVs (A) and erythrocytes (B) were incubated with $15 \mu \mathrm{M}\left[{ }^{3} \mathrm{H}\right]$ ribavirin for $15 \mathrm{sec}$ and $5 \mathrm{sec}$, respectively, in the absence (open symbol) or presence (closed symbol) of various concentrations of uridine at $23^{\circ} \mathrm{C}$. Each value represents the mean \pm S.E. of 3 determinations. $* \mathrm{p}<0.05, * * \mathrm{p}<0.01$, significantly different from the each control.

$\mathrm{nmol} / \mathrm{mg}$ protein/sec, respectively. When these values were compared with those of $\left[{ }^{3} \mathrm{H}\right]$ uridine uptake by ROVs, ribavirin transport was found to be low-affinity and high-capacity than uridine ${ }^{7)}$. Similar to the uptake by ROVs, $\left[{ }^{3} \mathrm{H}\right]$ ribavirin uptake by washed, intact erythrocytes showed saturation kinetics (Fig. 2B), and the $\mathrm{Km}$ and Vmax values were calculated to be $1.0 \mathrm{mM}$ and $76.3 \mathrm{pmol} / \mathrm{mg}$ protein $/ \mathrm{sec}$, respectively. Though the Vmax value could not be compared between these two experimental systems, $\mathrm{Km}$ value obtained in ROVs was higher (the apparent affinity was lower) than that in erythrocytes. EadieHofstee plots shown in the insets in Fig. 2A and B indicate that the single transport system would be involved in $\left[{ }^{3} \mathrm{H}\right]$ ribavirin uptake in both cases.

Carruthers ${ }^{14)}$ reported that transport properties such as $\mathrm{Km}$ and Vmax values of human erythrocyte glucose transporter were affected by ATP, an endogenous compound in the erythrocytes. In the literature, it was shown that $\mathrm{Km}$ value for D-glucose transport (efflux from IOVs) increased in the absence of ATP. Therefore, though the precise reason for the difference in $\mathrm{Km}$ value of ribavirin uptake between ROVs and erythrocytes is not known at this time, transport properties of ENT1 may be affected by endogenous compounds in the erythrocytes. Transport studies with membrane vesicles and comparison with those with intact erythrocytes would be useful to clarify the possible regulation of erythrocyte membrane transporters by intracellular compounds.

\subsection{Effects of uridine and ENT1 inhibitors on ribavirin uptake by ROVs and erythrocytes}

Jarvis et al. ${ }^{6}$ ) examined ribavirin uptake by intact erythrocytes and suggested that ribavirin is taken up by human erythrocytes by NBMPR-sensitive nucleoside transporter (ENT1). Therefore, the effect of uridine, a typical substrate of ENT1, and NBMPR and dipyridamole, inhibitors of ENT1, were examined. As shown in Fig. 3A, the uptake of $\left[{ }^{3} \mathrm{H}\right]$ ribavirin by ROVs was inhibited by uridine in a concentration-dependent manner with an $\mathrm{IC}_{50}$ value of $0.71 \mathrm{mM}(\gamma=1.0)$, indicating that ribavirin and uridine would be transported by a common transport system, most likely by ENT1. $\left[{ }^{3} \mathrm{H}\right]$ Ribavirin uptake by ROVs was also inhibited by another nucleoside, adenosine, with an $\mathrm{IC}_{50}$ value of $0.31 \mathrm{mM}(y=0.8)$. In order to confirm the role of ENT1 in ribavirin uptake by ROVs, the effect of NBMPR, a specific inhibitor of ENT115), was examined. As shown in Fig. 4A, $\left[{ }^{3} \mathrm{H}\right]$ ribavirin uptake by ROVs was inhibited by NBMPR in a concentration-dependent manner with an $\mathrm{IC}_{50}$ value of $58.2 \mathrm{nM}(\gamma=2.4)$. In addition, $\left[{ }^{3} \mathrm{H}\right]$ ribavirin uptake by ROVs was also inhibited by another ENT1 inhibitor, dipyridamole, with an $\mathrm{IC}_{50}$ value of $0.78 \mu \mathrm{M}(\gamma=4.4)$ (Fig. 5A). Similar inhibitory effects of uridine, NBMPR, and dipyridamole on $\left[{ }^{3} \mathrm{H}\right]$ ribavirin uptake were observed in erythrocytes, with $\mathrm{IC}_{50}$ values of $0.22 \mathrm{mM}(\gamma=0.9), 15.6 \mathrm{nM}(y=$ 1.9), and $0.69 \mu \mathrm{M}(\gamma=6.8)$, respectively (Figs. 3B, 4B, 

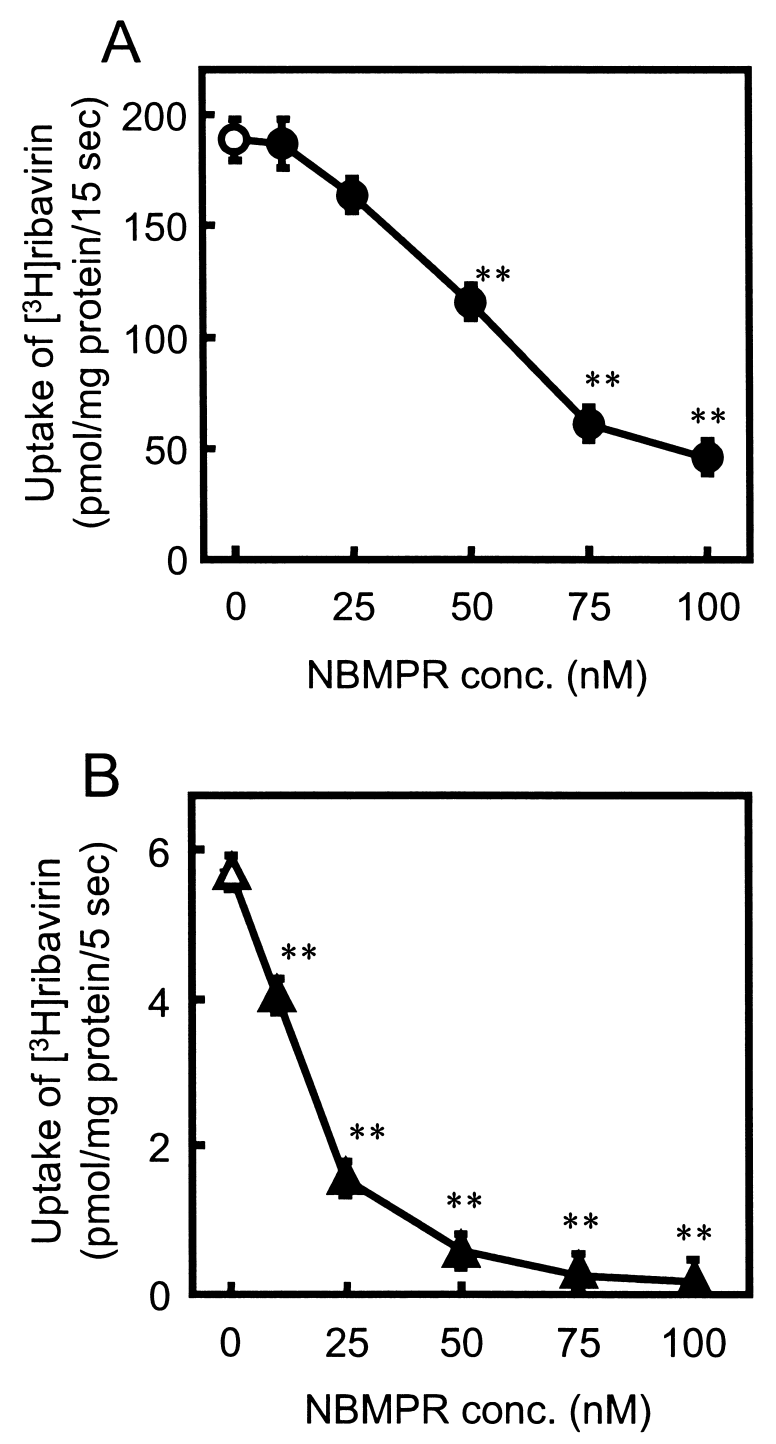

Fig. 4 Effects of NBMPR on $\left[{ }^{3} \mathrm{H}\right]$ ribavirin uptake by ROVs (A) and erythrocytes (B). ROVs (A) and erythrocytes (B) were incubated with $15 \mu \mathrm{M}\left[{ }^{3} \mathrm{H}\right]$ ribavirin for $15 \mathrm{sec}$ and $5 \mathrm{sec}$, respectively, in the absence (open symbol) or presence (closed symbol) of various concentrations of NBMPR at $23^{\circ} \mathrm{C}$. Each value represents the mean \pm S.E. of 3 determinations. $* * \mathrm{p}<0.01$, significantly different from the each control.

and $5 \mathrm{~B})$. The $\mathrm{IC}_{50}$ values obtained with erythrocytes were somewhat lower than those with ROVs. The results obtained with intact erythrocytes were comparable with those reported by Jarvis et al. ${ }^{\text {) }}$, but further studies are needed to clarify the possible ethnic and/or interindividual differences in the expression and function of ENT1 in human erythrocytes.

Mammalian nucleoside transporters can be classified into two structurally unrelated transporter families; equilibrative nucleoside transporters (ENT1-4;
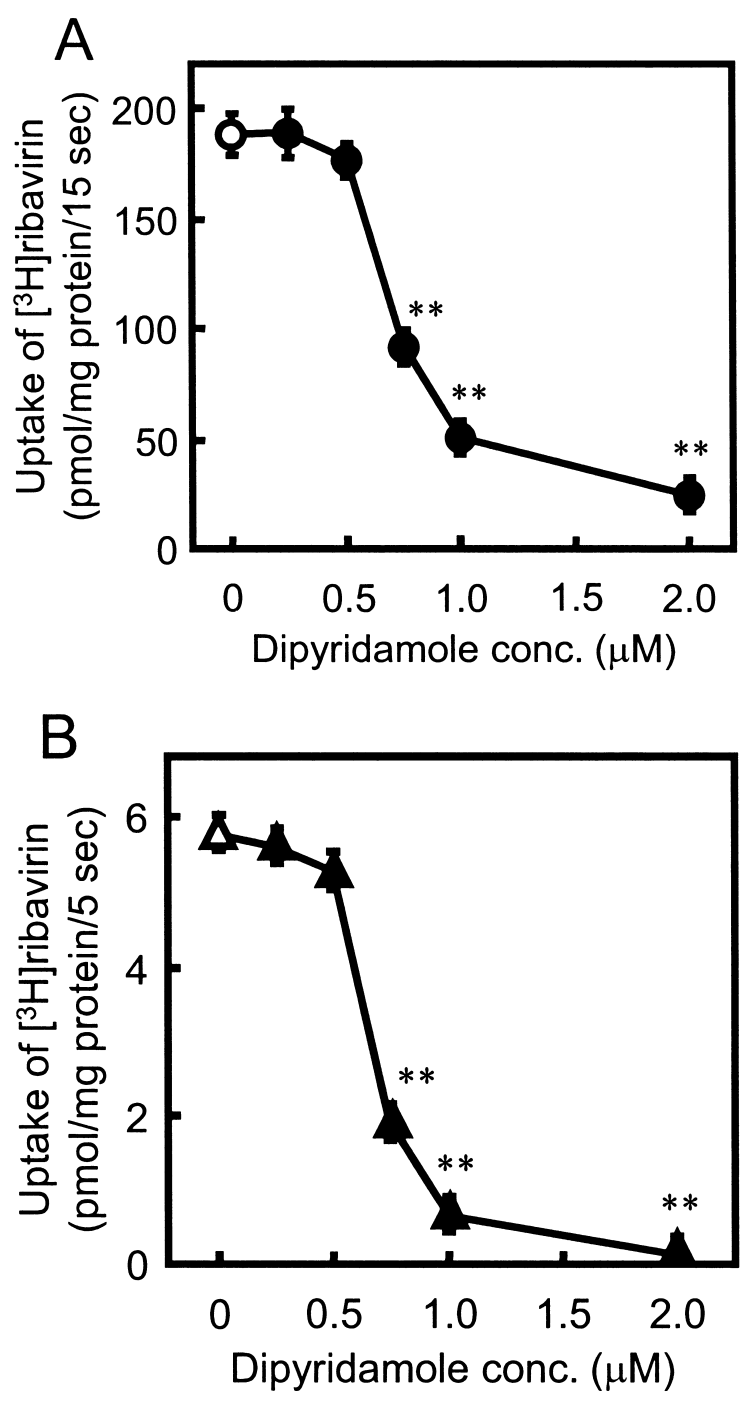

Fig. 5 Effects of dipyridamole on $\left[{ }^{3} \mathrm{H}\right]$ ribavirin uptake by ROVs (A) and erythrocytes (B). ROVs (A) and erythrocytes (B) were incubated with $15 \mu \mathrm{M}\left[{ }^{3} \mathrm{H}\right]$ ribavirin for $15 \mathrm{sec}$ and $5 \mathrm{sec}$, respectively, in the absence (open symbol) or presence (closed symbol) of various concentrations of dipyridamole at $23{ }^{\circ} \mathrm{C}$. Each value represents the mean \pm S.E. of 3 determinations. $* * \mathrm{p}<0.01$, significantly different from the each control.

SLC29A1-4) and $\mathrm{Na}^{+}-$dependent concentrative nucleoside transporters (CNT1-3; SLC28A1-3) ${ }^{16}$. These nucleoside transporters play important roles in nucleoside and nucleobase uptake for salvage pathways of nucleotide synthesis, and in the cellular uptake of nucleoside analogue drugs used in the treatment of cancers and viral diseases. In addition, these nucleoside transporters are potential therapeutic targets, and nucleoside transport inhibitors including dipyridamole modulate various physiological processes, leading to pharmacological effects ${ }^{16,17)}$. Human ENT1 is widely 

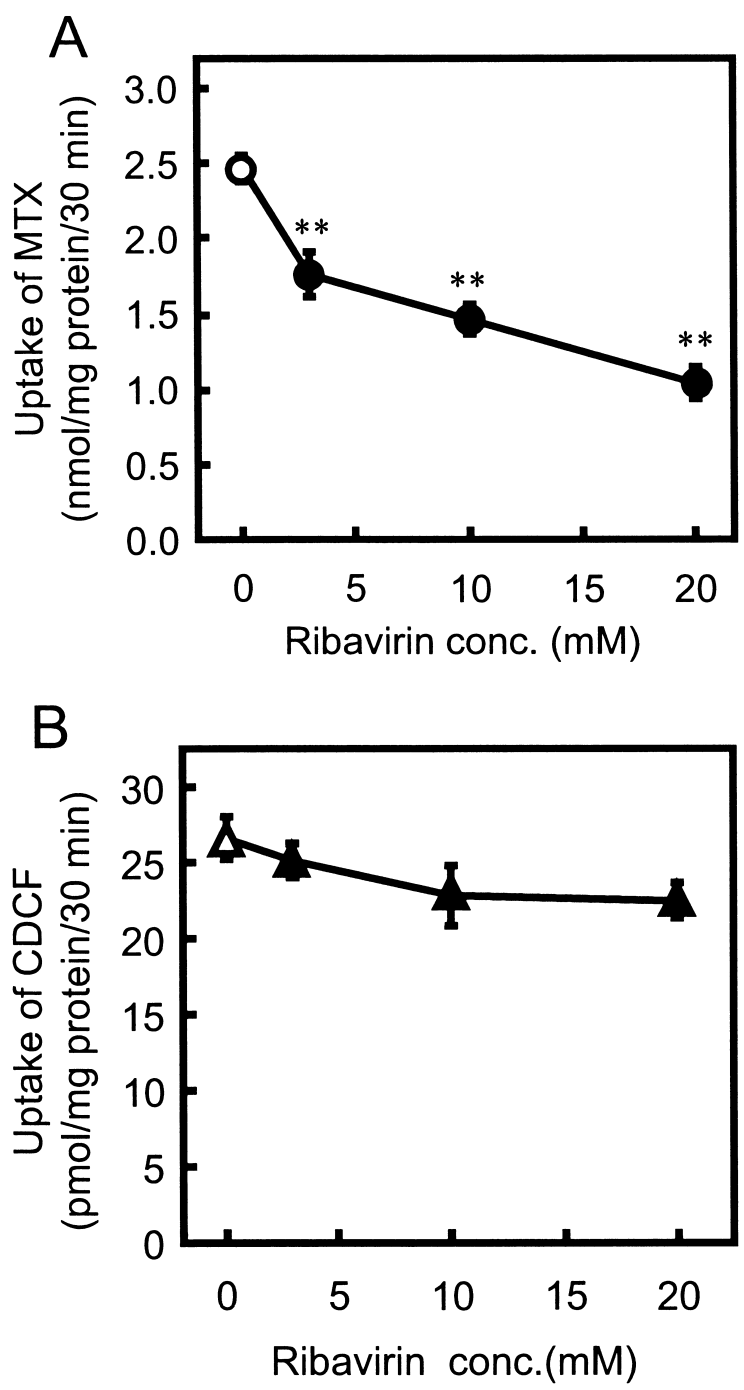

Fig. 6 Effects of ribavirin on MTX (A) and CDCF (B) uptake by IOVs. IOVs were incubated with $15 \mu \mathrm{M}$ MTX (A) and $5 \mu \mathrm{M} \mathrm{CDCF} \mathrm{(B)} \mathrm{for} 30 \mathrm{~min}$ in the absence (open symbol) or presence (closed symbol) of various concentrations of ribavirin at $37{ }^{\circ} \mathrm{C}$. Each value represents the mean \pm S.E. of 3 determinations. $* * \mathrm{p}<0.01$, significantly different from the control.

distributed in various tissues, including erythrocytes, liver, heart, spleen, kidneys, lungs, intestines, and brain ${ }^{17}$. We also confirmed the expression of ENT1 protein by Western blotting in ROVs that we have prepared $^{7}$. On the other hand, there has been no report indicating the expression of CNT in erythrocyte membranes. In order to examine whether CNT is functionally expressed in human erythrocyte or not, we examined the effect of $\mathrm{Na}^{+}$gradient on $\left[{ }^{3} \mathrm{H}\right]$ uridine uptake by ROVs. However, no effect of $\mathrm{Na}^{+}$gradient on the uptake was observed (data not shown), supporting that CNT is not expressed in human erythrocytes.

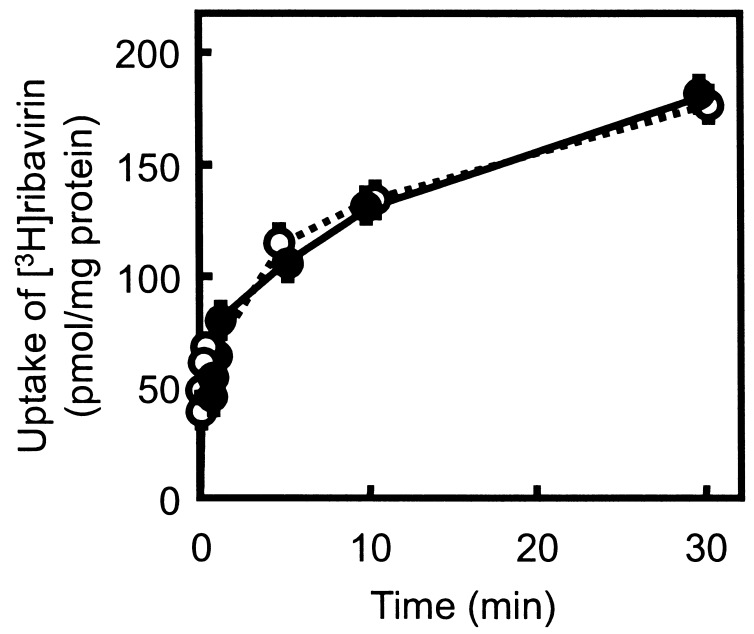

Fig. 7 ATP-dependence of $\left[{ }^{3} \mathrm{H}\right]$ ribavirin uptake by IOVs. The uptake of $15 \mu \mathrm{M}\left[{ }^{3} \mathrm{H}\right]$ ribavirin was measured at $37^{\circ} \mathrm{C}$ in the presence of $1 \mathrm{mM}$ ATP (closed circle) or $1 \mathrm{mM}$ AMP (open circle). NBMPR $(1 \mu \mathrm{M})$ was added in the uptake buffer and stop solution to prevent ENT1-mediated transport of $\left[{ }^{3} \mathrm{H}\right]$ ribavirin. Each value represents the mean \pm S.E. of 3 determinations.

Recently, Endres et al. ${ }^{18)}$ examined the role of ENT1 in ribavirin uptake using wild-type and ENT1(-/-) mouse erythrocytes, and clearly showed that ENT1 is responsible for the uptake of ribavirin in mouse erythrocytes. Taken together, the transporter involved in ribavirin uptake by human erythrocytes would be ENT1.

\subsection{Interaction of ribavirin with efflux trans- porters in human erythrocyte membranes}

Multidrug resistance-associated proteins (MRPs) are members of adenosine-5'-triphosphate (ATP)binding cassette $(\mathrm{ABC})$ transporter superfamily, and function as ATP-dependent efflux transporters ${ }^{19}{ }^{20)}$. Human MRP family contains 9 members; MRP1 (ABCC1), MRP2 (ABCC2), MRP3 (ABCC3), MRP4 (ABCC4), MRP5 (ABCC5), MRP6 (ABCC6), MRP7 (ABCC10), MRP8 (ABCC11), and MRP9 (ABCC12). Among these MRPs, MRP1, MRP4 and MRP5 have been detected in human erythrocyte membranes ${ }^{21,22)}$. We have recently reported the transport characteristics of MRP4 and MRP5 using human erythrocyte IOVs and MTX and CDCF as each substrate ${ }^{12)}$. Though there has been no study indicating the role of MRPs in ribavirin transport, it is reported that some nucleoside analogues such as ganciclovir and lamivudine are substrates of MRP4 and mercaptopurine and thioguanine 
are substrates of MRP4 and MRP523). Therefore, the interaction of ribavirin with MRP4 and MRP5 was examined using IOVs. ATP-dependent uptake of MTX, which is predominantly mediated by MRP4, was significantly inhibited by ribavirin in a concentrationdependent manner (Fig. 6A), though millimolar concentrations of ribavirin were needed for the inhibition. The uptake of MTX was also inhibited by uridine (data not shown). On the other hand, ATP-dependent uptake of $\mathrm{CDCF}$, which is predominantly mediated by MRP5, was not significantly affected by ribavirin (Fig. 6B). Therefore, ribavirin and uridine may interact with MRP4 but not with MRP5. To further clarify the role of MRPs in ribavirin transport across erythrocyte membranes, the effect of ATP on $\left[{ }^{3} \mathrm{H}\right]$ ribavirin uptake was examined (Fig. 7). In this experiment, NBMPR was added in the uptake buffer and stop solution to prevent ENT1-mediated transport of $\left[{ }^{3} \mathrm{H}\right]$ ribavirin during uptake and washing processes. NBMPR did not affect MRP4-mediated uptake of MTX (data not shown). In contrast to MTX and CDCF uptake, however, no ATP-dependence was observed in $\left[{ }^{3} \mathrm{H}\right]$ ribavirin uptake by IOVs. Thus, though ribavirin weakly interacted with MRP4, ribavirin itself would not be transported by MRP4.

In conclusion, the role of ENT1 in ribavirin transport across human erythrocyte membranes was clearly shown at the membrane level. In addition, it was found that ATP-dependent efflux transporters would not be involved in ribavirin transport in erythrocytes. Thus, ENT1 should be a crucial transporter that determines ribavirin level in human erythrocytes and therefore ribavirin-induced erythrocytopenia.

\section{Acknowledgements}

This work was supported in part by a Grant-in-Aid for Scientific Research from the Ministry of Education, Science, Sports, and Culture in Japan.

\section{References}

1) Maeda Y, Kiribayashi Y, Moriya T, Maruhashi A, Omoda K, Funakoshi S, Murakami T, Takano M : Ther. Drug Monit., 26, 9-15 (2004)

2) Chutaputti A : J. Gastroenterol. Hepatol., 15, 156-163 (2000)

3) Page T, Connor JD : Int. J .Biochem., 22, 379-383 (1990)

4) Russmann S, Grattagliano I, Portincasa P, Palmieri VO, Palasciano G : Current. Medicinal. Chemistry, 13, 33513357 (2006)
5) Canonico PG, Kastello MD, Spears CT, Brown JR, Jackson EA, Jenkins DE : Toxicol. Appl. Pharmacol., 74, 155-162 (1984)

6) Jarvis SM, Thorn JA, Glue P : Br. J. Pharmacol., 123, 1587-1592 (1998)

7) Takano M, Kimura E, Suzuki S, Nagai J, Yumoto R: Drug Metab. Pharmacokinet., in press (2010)

8) Deeba F, Tahseen HN, Sharad KS, Ahmad N, Akhtar S, Saleemuddin M, Mohammad O : Biochim. Biophy. Acta, 1669, 170-181 (2005)

9) Klonk S, Deuticke B : Biochim. Biophy. Acta, 1106, 143150 (1992)

10) Takano M, Inui K, Okano $T$, Saito $H$, Hori $R$ : Biochim. Biophys. Acta, 773, 113-124 (1984)

11) Ogawa K, Yumoto R, Hamada N, Nagai J, Takano M : Epilepsy Res., 7 1, 76-87 (2006)

12) Yumoto R, Yamakawa K, Nagai J, Takano M : Membrane, 34, 152-158 (2009)

13) Bradford MM : Anal. Biochem., 72 248-254 (1976)

14) Carruthers A : J. Biol. Chem., 261, 11028-11037 (1986)

15) Thorn JA, Jarvis SM : Gen Pharmacol. 27, 613-620 (1996)

16) King AE, Ackley MA, Cass CE, Young JD, Baldwin SA : Trends Pharm. Sci., 27, 416-425 (2006)

17) Baldwin SA, Beal PR, Yao SYM, King AE, Cass CE, Young JD : Pflugers Arch. Eur. J. Physiol., 447, 735-743 (2004)

18) Endres CJ, Moss AM, Ke B, Govindarajan R, Choi DS, Messing RO, Unadkat JD : J. Pharmacol. Exp. Ther., 329, 387-398 (2009)

19) Takano M, Yumoto R, Murakami T : Pharmacol. Ther., 109, 137-161 (2006)

20) Takano M, Murakami T : Expert Opin. Drug Metab. Toxicol., 4, 923-939 (2008)

21) Klokouzas A, Wu CP, Van Veen HW, Barrand MA, Hladky SB : Eur. J. Biochem., 270, 3696-3708 (2003)

22) Köck K, Grube M, Jedlitschky G, Oevermann L, Siegmund W, Ritter CA, Kroemer HK : Clin. Pharmacokinet., 46, 449-470 (2007)

23) Ritter CA, Jedlitschky G, Meyer zu Schwabedissen H, Grube M, Köck K, Kroemer HK : Drug Metab. Rev., 37, 253-278 (2005)

(Received 20 July 2010;

Accepted 1 September 2010) 